\title{
General Discussion to Papers of Dr Minaire et al., Dr Ragnar Gjone and Nordlie, Dr Than Toe, Dr Kewalramani, Dr Shrosbree et al., Dr Pool
}

Professor RoAf (G.B.). First of all I would like to say what is obvious, how very good these papers are and interesting, but my question was whether they have any statistics about the relative incidence of spine injuries, these are the spinal cord injuries. The reason I ask this is that if the same directional force is responsible either for the spine injury or spine plus spinal cord injury and if it is merely a question of a lesser force producing the spine injury without spinal cord involvement, this would give us a very valuable idea of whether various prophylactic measures to prevent these serious injuries were of any value or not. So the question has got some practical significance. I wonder if any of the speakers can give me information on this.

DR FRANKEL (G.B.). When three proffered papers of this nature are presented it makes the work of a programme committee very easy and makes the papers much more valuable. I should like to comment on Dr Minaire's evaluation from these figures, from the incidence to the prevalence of paraplegia. I think the way to determine the prevalence is to measure it. I know it's difficult to do so but I feel it is extremely inaccurate in a changing situation with increasing survival to even estimate what the prevalence is from the incidence.

Dr Kewalramani (U.S.A.). With reference to Minaire's paper, I definitely agree with him. Some of the data he reported for a California study and I was part of that study. The important contribution of that study was that we included all patients who sustained injury to the spine and the spinal cord. They were not individuals who were only admitted at the hospital. We went around to different data, from the coroner's reports, from Workmen's Compensation records, from State services and we contacted some I25 hospitals. All medical records including X-rays were exhaustively analysed but definitely I think here in most of these papers we are using the term incidence inaccurately, because incidence means we have to include all the patients, all the individuals who sustained injury to the spine, and we should include the dead individuals also. The California study had incidents of 55 per million or 5.5 per cent per million. The individuals who died were, of the 6I4 individuals who sustained injury to the spine, 299 died; that gives the survival of somewhere 3.32 per hundred thousand. But it becomes even more important when we analyse the data for paediatric population, individuals less than I5 years of age, this fatality rate was 85 per cent, so I think you know we are using the term here a little bit inaccurately when we are describing the patients only admitted at the hospital.

Dr Agerholm (G.B.). One of the joys of this sort of international meeting is that we do get some of our experiments and research done for us by the very fact that people are collecting material in different places. I would like to comment on the absence of pulmonary embolism and deep venous thrombosis in Burma, the easy treatment of it in Sheffield and the failure of that exact treatment in Australia. I do think that we really ought to learn the lesson from this. I once lived in a hospital in Oxford, where we were dealing with exactly the same kind of cases in our English hospital as the Americans were dealing with literally over the other side of the road. I never saw a case of pulmonary embolism; at that time we were on a very strict dietary regime. We never got down to discovering.

DR Than Toe (Burma). The figures I've quoted were of patients admitted to the Rangoon General Hospital and later transferred to our Rehabilitation Hospital. Rangoon itself has about $2 \frac{1}{2}$ million people population and over all Burma there is about 30 million population. I'm trying to confine myself only to the Rangoon division because I haven't got the exact sort of incidence in other areas. We only started the spinal injuries unit, I mean as a proper basis, a few years back when I got back to Burma. That's why I didn't want to comment about people's incidence.

DR MINAIRE. Would you say that the number of deep venous thrombosis in North Africa is much lower than in the French population? I have no figure about the incidence, 
the number of fractures with or without spinal cord involvement. I guess there is a recent study in the U.S.A. dealing with these particular subjects. About Dr Frankel's remark about the prevalence, it is true that it would be even dangerous, but I would give you some reply to Dr Kewalramani that for us the problem is economical. I am interested in living people and I am interested in giving my government authorities some figures about the need for rehabilitation, to the insurance companies in France some figures about the cost, and I think it was best studying this way. I know that from a strict epidemiological point of view the term of incidence is overstressed in my study and I know it. But it's very difficult to get it to appear in the title so that the dead on arrival were not included.

Dr CHEShIRE (U.S.A.). I'd like to make comment on Dr Kewalramani's excellent paper on diving injuries, and I'm suddenly impelled to do so because he quotes and doubts the work of my colleague Burke which includes in fact a great number of patients who were under my care. I would firstly give Dr Kewalramani total assurance that the patients reported in Burke's paper did sustain what we may now call axial loading fractures, and they did in the majority of cases have visible evidence of forehead or scalp injury. This I think is not unrelated to the predominance of diving into irrigation ditches and on to rock in Australia. The next thing is that I have certainly myself seen a change in the pattern since I came to the United States. There are more people who are diving into deeper water, who are diving into swimming pools and there are not so many frank burst fractures. But why I would really like to take issue with Dr Kewalramani is his contention that there were I09 cases of total tetraplegia caused by wedge fractures. A wedge fracture is a flexion injury causing a wedge deformity of a vertebral body but with retention of integrity of the posterior ligamentous complex. This I think is an extremely rare skeletal injury, to be associated with total tetraplegia, and I think I will not accept Dr Kewalramani's contention of wedge fractures unless he tells me that in every case he performed functional films to demonstrate whether or not the posterior ligamentous complex was intact. I suggest the probability is that we were dealing with a flexion rotation fracture subluxation which was spontaneously reduced during supine carriage to hospital.

DR Kewalramani (U.S.A.). I knew when I was quoting Dr Burke's paper that I was putting my hand in a hornet's nest seeing Dr Cheshire here. I wasn't doubting the adequacy of evaluation since from that 1972 paper quoted in an Australian journal of medicine on 52 patients, there was no reference to evidence of injury to the scalp. In my publication in 1975 I quoted Burke saying that because of the presence of 88 per cent burst fractures, there were burst as well as wedge fractures, the 40 patients I mentioned who had two level fractures, there were about half of them who had burst as well as wedge fractures. Now as to the Io9 tetraplegics with burst fractures, a number of those patients have had evidence of posterior neural arch fracture as well as evidence of interspinous space increase. The description of that wedge fracture as I showed you here.

DR L. Michaelis (G.B.). I thought I ought to make sure that nobody overlooks the rare fact that we have been told by Dr Shrosbree of a new cause, or so far unknown cause, of spinal injury by bearing heavy loads on their heads, and I think it is a very remarkable paper he has shown us. This is one thing; the other thing which interests me even more, if I'm not mistaken, the surface of the cervical vertebrae from the last lateral film shown and their height differed from normal. The cervical vertebrae were wider and were much lower than normal cervical vertebrae. In fact they looked to me like the opposite to the giraffe's neck vertebrae which are higher than normal. Would you kindly tell me whether any research has been done on these functional changes produced by early burden loading on young cervical spines?

Dr Shrosbree ( $S$. Africa). Dr Michaelis, unfortunately no, we have just recently become very interested in this since we've had several cases in, and up to now as far as I know no research has been done except Levy's original study, I think it was in I960. We actually did a similar paper, I'm not sure where it was published; unfortunately I haven't got the references of Dr Scher's published paper. 